\title{
Erratum to: Crop Residue Considerations for Sustainable Bioenergy Feedstock Supplies
}

\author{
Douglas L. Karlen • Jane M. F. Johnson
}

Published online: 21 May 2014

(C) Springer Science+Business Media New York 2014

Erratum to: Bioenerg Res (2014) 7:465-467

DOI 10.1007/s12155-014-9407-y

Two regrettable errors occurred in citing a critical funding source for the multi-location research summarized in the 2014 article entitled "Crop Residue Considerations for Sustainable Bioenergy Feedstock Supplies" by Douglas L. Karlen and Jane M. F. Johnson (BioEnergy Research 7:465-467 DOI 10.1007/ s12155-014-9407-y).

Within the abstract, the sentence stating that: "This overview highlights ... as part of the National Institute for Food and Agriculture Sun Grant Regional Feedstock Partnership Corn Stover Team" should read "This overview highlights ... as part of the Department of Energy Bioenergy Technologies Office's Regional Feedstock

\section{Partnership Corn Stover Team (as part of the Sun Grant Initiative).}

Also, in the second paragraph of the article, the sentence stating that: "The SOC and GHG concerns ... Therefore, working through the Office of Biomass Products" (now known as the Biomass Energy Technology Office the DOE ... through the NIFA Sun Grant Association to address those needs" should read "The SOC and GHG concerns ... through the DOE Bioenergy Technologies Office, the DOE ... through the Sun Grant Initiative to address those needs."

We deeply regret these errors and want the readers of BioEnergy Research to know that the USDA-ARS Resilient Economic Agricultural Practices (formerly the Renewable Energy Assessment Project) REAP team is very grateful for the collaborative research that was enhanced by these DOE fiscal resources.

The online version of the original article can be found at http://dx.doi.org/ 10.1007/s12155-014-9407-y.

D. L. Karlen $(\bowtie)$

USDA-Agricultural Research Service (ARS), National Laboratory for Agriculture and the Environment (NLAE), 2110 University

Boulevard, Ames, IA 50011, USA

e-mail: Doug.Karlen@ars.usda.gov

J. M. F. Johnson

USDA-ARS-North Central Soil Conservation Research Laboratory

(NCSCRL), Morris, MN 56267, USA 